\title{
A STUDY ON ABSOLUTE EULER TOTIENT SERIES SPACE AND CERTAIN MATRIX TRANSFORMATIONS
}

\author{
Merve İLKHAN, Department of Mathematics, Duzce University, Turkey, merveilkhan@duzce.edu.tr \\ (iD) https://orcid.org/0000-0002-0831-1474) \\ *G. Canan HAZAR GÜLEÇ, Department of Mathematics, Pamukkale University, Turkey, gchazar@pau.edu.tr \\ (D) https://orcid.org/0000-0002-8825-5555)
}

\begin{abstract}
Recently, many authors have focused on the studies related to sequence and series spaces. In the literature the simple and fundamental method is to construct new sequence and series spaces by means of the matrix domain of triangular matrices on the classical sequence spaces. Based on this approach, in this study, we introduce a new series space $\left|\phi_{z}\right|_{p}$ as the set of all series summable by absolute summability method $\left|\Phi, z_{n}\right|_{p}$, where $\Phi=\left(\phi_{n k}\right)$ denotes Euler totient matrix, $z=\left(z_{n}\right)$ is a sequence of non-negative terms and $p \geq 1$. Also, we show that the series space $\left|\phi_{z}\right|_{p}$ is linearly isomorphic to the space of all $p$-absolutely summable sequences $\ell_{p}$ for $p \geq 1$. Moreover, we determine some topological properties and $\alpha, \beta$ and $\gamma$-duals of this space and give Schauder basis for the space $\left|\phi_{z}\right|_{p}$. Finally, we characterize the classes of the matrix operators from the space $\left|\phi_{z}\right|_{p}$ to the classical spaces $\ell_{\infty}, c, c_{0}, \ell_{1}$ for $1 \leq p<\infty$ and vice versa.

Keywords: Absolute Series Spaces, Matrix Operators, BK Spaces.
\end{abstract}

\section{MUTLAK EULER TOTIENT SERİ UZAYI VE BAZI MATRİS DÖNÜŞÜMLERİ ÜZERÍNE BİR ÇALIŞMA}

\section{Özet}

Son zamanlarda birçok yazar dizi ve seri uzayları ile ilgili çalışmalara yoğunlaşmışlardır. Literatürde basit ve temel yaklaşım klasik dizi uzayları üzerinde üçgensel matrislerin matris etki alanı yardımıyla yeni dizi ve seri uzayları inşa etmektir. Bu çalışmada, bu yaklaşımdan yola çıkarak $\left|\Phi, z_{n}\right|_{p}$ mutlak toplanabilme metodu ile toplanabilen tüm serilerin uzayı olan yeni bir $\left|\phi_{z}\right|_{p}$ seri uzayı tanımlanmıștır, burada $\Phi=\left(\phi_{n k}\right)$ Euler totient matrisini gösterir, $z=\left(z_{n}\right)$ terimleri negatif olmayan bir dizidir ve $p \geq 1$ dir. $\left|\phi_{z}\right|_{p}$ seri uzayının tüm mutlak $p$ - toplanabilen dizilerin $\ell_{p}, p \geq 1$, uzayına izomorf olduğu gösterilmiştir. Ayrıca, bu uzayın bazı topolojik özellikleri ile $\alpha, \beta$ and $\gamma$-dualleri belirlenmiştir ve $\left|\phi_{z}\right|_{p}$ uzayı için Schauder bazı verilmiştir. Son olarak, $\left|\phi_{z}\right|_{p}$ uzayından $\ell_{\infty}, c, c_{0}, \ell_{1}$ klasik dizi uzaylarına ve $\ell_{\infty}, c, c_{0}, \ell_{1}$ klasik dizi uzaylarından $\left|\phi_{z}\right|_{p}$ uzayına bazı matris operatörleri karakterize edilmiştir.

Anahtar Kelimeler: Mutlak Seri Uzayları, Matris Operatörleri, BK Uzayları.

Cite

İlhan, M., Hazar Güleç, G. C., (2020). "A study on absulute euler totient series space and certain matrix transformations”, Mugla Journal of Science and Technology, 6(1), 112-119.

\section{Introduction}

Let $\omega$ be the space of all real valued sequences. Each linear subspace of $\omega$ is called a sequence space. We write $\psi, \ell_{\infty}, c$ and $c_{0}$ for the sequence spaces of all finite, bounded, convergent, null sequences and also by $b s, c s$ and $\ell_{p} \quad(1 \leq p<\infty)$, we denote the spaces of all bounded, convergent and $p$-absolutely convergent series, respectively. Throughout the paper $q$ denotes the conjugate of $p>1$, i.e., $1 / p+1 / q=1$, and $1 / q=0$ for $p=1$.

For the sequence spaces $\mathrm{X}$ and $\mathrm{Y}$, define the set $S(X: Y)$ by

$$
\begin{gathered}
S(X: Y)=\left\{u=\left(u_{k}\right) \in \omega: x u=\left(x_{k} u_{k}\right) \in Y\right. \\
\text { for all } x \in X\} .
\end{gathered}
$$

With the notation in (1), $\alpha, \beta$ and $\gamma$-duals of a sequence space $X$, which are denoted by $X^{\alpha}, X^{\beta}$ and $X^{\gamma}$ respectively, are defined by $X^{\alpha}=S\left(X: \ell_{1}\right), X^{\beta}=$ $S(X: c s)$ and $X^{\gamma}=S(X: b s)$.

Let $A=\left(a_{n k}\right)$ be an infinite matrix of real numbers and $X, Y$ be non-empty subsets of $\omega$. We say that $A$ defines a matrix mapping from $X$ to $Y$, and we denote it by $A: X \rightarrow Y$, if for every sequence $x=\left(x_{k}\right) \in X$, $A x=\left(A_{n}(x)\right)$, the $A$-transform of $x$, is in $Y$, where the 
series $A_{n}(x)=\sum_{k=1}^{\infty} a_{n k} x_{k}$ convergences for all $n$. By $(X, Y)$, we denote the class of all such matrices.

For any subset $X$ of $\omega$, the matrix domain $X_{A}$ is introduced by

$$
X_{A}=\{x \in \omega: A x \in X\} .
$$

A $B K$ space $X \subset \omega$ is a Banach space with continuous coordinates $P_{n}: X \rightarrow \mathbb{C}$, where $P_{n}(x)=x_{n}$ for all $x \in X$, $n \geq 1$ and $\mathbb{C}$ denotes the complex field. Also, a $B K$ - space $X \supset \psi$ is said to have $A K$ if every sequence $x \in X$ has a unique representation $x=\sum_{k=1}^{\infty} x_{k} e^{(k)}$, where $e^{(k)}$ denotes the sequence with $e_{k}^{(k)}=1$ and $e_{j}^{(k)}=0$ for $j \neq k$ [1]. For example, the sequence spaces $\ell_{\infty}, c$ and $c_{0}$ are $B K$-spaces with the norm given by $\|x\|_{\ell_{\infty}}=$ $\sup _{k}\left|x_{k}\right|$ and $\ell_{p}$ is a $B K$-space with the norm $\|x\|_{\ell_{p}}=\left(\sum_{k=1}^{\infty}\left|x_{k}\right|^{p}\right)^{1 / p}, \quad 1 \leq p<\infty$. Moreover, the spaces $c_{0}$ and $\ell_{\mathrm{p}}(1 \leq p<\infty)$ have the property $A K$.

If $A=\left(a_{n k}\right)$ is an infinite triangle matrix, i.e., $a_{n n} \neq 0$, and $a_{n k}=0$ for $k>n$, there exists its unique inverse [2].

For a given $m \in \mathbb{N}$ with $m>1$, Euler totient function $\varphi$ is defined as the number of positive integers less than $m$ that are coprime with $m$ and $\varphi(1)=1$.

If two numbers $m$ and $n$ are coprime, then $\varphi(m n)=$ $\varphi(m) \varphi(n)$ and also $m=\sum_{d \mid m} \varphi(d)$ holds.

Consider the infinite matrix $\Phi=\left(\phi_{n k}\right)$ such that

$$
\phi_{n k}= \begin{cases}\frac{\varphi(k)}{n}, & \text { if } k \mid n \\ 0, & \text { if } k \nmid n .\end{cases}
$$

Schoenberg [3] has proved that this matrix is regular and defined that a sequence $\left(x_{n}\right)$ of real numbers is $\varphi$-convergent to $\xi \in \mathbb{R}$ if

$$
\lim _{n \rightarrow \infty} \frac{1}{n} \sum_{d \mid n} \varphi(d) x_{d}=\xi
$$

This regular matrix is called as Euler totient matrix operator in [4] and some new sequence spaces have been introduced by using this matrix.

For any given $m \in \mathbb{N}$ with $m>1$, Möbius function $\mu$ is defined as

$\mu(m)$

$$
= \begin{cases}(-1)^{r} & \text { if } m=p_{1} p_{2} \ldots p_{r}, \text { where } p_{1}, p_{2}, \ldots, p_{r} \text { are } \\ 0 & \text { non equivalent prime numbers } \\ 0 & \text { if } p^{2} \mid m \text { for some prime number } p\end{cases}
$$

and $\mu(1)=1$. Also, if two numbers $m$ and $n$ are coprime, then $\mu(m n)=\mu(m) \mu(n)$ and $\sum_{d \mid m} \mu(d)=0$ holds except for $m=1$.

Let $\sum x_{n}$ be infinite series with $n$th partial sum $s_{n}$ and $\left(z_{n}\right)$ be a sequence of non-negative terms. The series $\sum x_{n}$ is said to be summable $\left|A, z_{n}\right|_{p}, p \geq 1$, if

$$
\sum_{n=1}^{\infty} z_{n}^{p-1}\left|\Delta A_{n}(s)\right|^{p}<\infty
$$

where $\Delta A_{n}(s)=A_{n}(s)-A_{n-1}(s)$, for $n \geq 1$ [5]. This method includes the most of well known absolute summability methods. For example, if we take A as matrix of weighted mean $\left(\bar{N}, t_{n}\right)$ (resp. $\left.z_{n}=T_{n} / t_{n}\right)$, then summability $\left|A, z_{n}\right|_{p}$ reduces to summability methods $\left|\bar{N}, t_{n}, z_{n}\right|_{p}$ (resp. $\left|\bar{N}, t_{n}\right|_{p}$ [6]) [7], where $t_{n}>0$ for all $n$ and $T_{n}=\sum_{k=0}^{n} t_{k} \rightarrow \infty$ as $n \rightarrow \infty$. Further, if $A$ is matrix of Nörlund mean $\left(N, t_{n}\right)$, then summability $\left|A, z_{n}\right|_{p}$ is same as the summability $\left|N, t_{n}\right|_{p}$ given by Borwein and Cass [8] with $z_{n}=n$ for $n \geq 1$, which also includes absolute Cesàro summability $|C, \alpha|_{p}$ of Flett [9], where $\left(t_{n}\right)$ is a sequence of complex numbers with $T_{n}=\sum_{k=0}^{n} t_{k} \neq 0, t_{0} \neq 0, T_{-n}=0$ for $n \geq 1$. In addition to all these classical methods, if we take $A$ as Euler totient matrix $\Phi=\left(\phi_{n k}\right)$, we obtain a new absolute summability method $\left|\Phi, z_{n}\right|_{p}$.

Many authors have constructed sequence spaces by means of the matrix domain of triangles on the classical sequence spaces. For some of the papers and applications, we refer to [10-31] and references therein. In this paper, we introduce a new series space by using the Euler totient matrix and determine $\alpha, \beta$ and $\gamma$-duals of this space. Finally, we characterize the classes of matrix operators between the classical spaces $\ell_{\infty}, c, c_{0}, \ell_{1}$ and this new space.

\section{The Series Space $\left|\phi_{z}\right|_{p}$}

Now, we introduce the series space $\left|\phi_{z}\right|_{p}$ as the set of all series summable by absolute summability method $\left|\Phi, z_{n}\right|_{p}$ as follows.

$$
\left|\phi_{z}\right|_{p}=\left\{x=\left(x_{n}\right) \in \omega: \sum_{n=1}^{\infty} z_{n}^{p-1}\left|\Delta \Phi_{n}(s)\right|^{p}<\infty\right\},
$$

where $\left(\Phi_{n}(s)\right)$ Euler totient transform of the sequence $\left(s_{n}\right)$, that is, $\Phi_{n}(s)=\sum_{k=1}^{\infty} \phi_{n k} s_{k}$.

Note that since $\left(s_{n}\right)$ is the sequence of partial sum of infinite series $\sum x_{n}$, we can write Euler totient transform $\left(\Phi_{n}(s)\right)$ of the sequence $\left(s_{n}\right)$ by

$$
\begin{array}{r}
\Phi_{n}(s)=\sum_{k=1}^{\infty} \phi_{n k} s_{k}=\sum_{k=1}^{n} \phi_{n k} \sum_{j=1}^{k} x_{j} \\
=\sum_{j=1}^{n} x_{j} \sum_{\substack{k=j \\
k \mid n}}^{n} \frac{\varphi(k)}{n} .
\end{array}
$$

Thus, we obtain that

$$
\left|\phi_{z}\right|_{p}=\left\{x=\left(x_{n}\right) \in \omega:\right.
$$




$$
\begin{gathered}
\sum_{n=1}^{\infty} z_{n}^{p-1} \mid \sum_{j=1}^{n-1} x_{j}\left(\sum_{\substack{k=j \\
k \mid n}}^{n} \frac{\varphi(k)}{n}-\sum_{\substack{k=j \\
k \mid n-1}}^{n-1} \frac{\varphi(k)}{n-1}\right) \\
\left.+\left.x_{n} \frac{\varphi(n)}{n}\right|^{p}<\infty\right\} .
\end{gathered}
$$

If we define the matrices $E^{(p)}=\left(e_{n k}^{(p)}\right), 1 \leq p<\infty$ and $F=\left(f_{n k}\right)$ by

$$
e_{n k}^{(p)}=\left\{\begin{array}{c}
-z_{n}^{1 / q}, k=n-1 \\
z_{n}^{1 / q}, k=n \\
0, \text { otherwise }
\end{array}\right.
$$

and

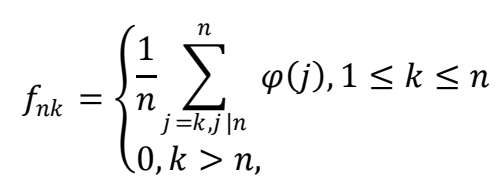

then, we can write that $\left(E^{(p)} \circ F\right)_{n}(x)=z_{n}^{1 / q}\left(F_{n}(x)-\right.$ $\left.F_{n-1}(x)\right)$ for $n \geq 1$, where $F_{n}(x)=\sum_{j=1}^{n} \underset{\substack{k=j \\ k \mid n}}{x_{j}} \frac{\varphi(k)}{n}$ and $F_{0}(x)=0$.

So we may restate $\left|\phi_{z}\right|_{p}=\left(\ell_{p}\right)_{\left.E^{(p)}\right)_{\circ F}}$ according to the notation of matrix domain (2).

Also, since the matrices $E^{(p)}$ and $F$ are triangles, they have the unique inverses and we denote these inverses by $\left(E^{(p)}\right)^{-1}=\hat{E}^{(p)}$ and $F^{-1}=\hat{F}$ for brevity. Further, we can calculate these matrices $\hat{E}^{(p)}=\left(\hat{e}_{n k}^{(p)}\right)$ and $\hat{F}=\left(\hat{f}_{n k}\right)$ by

$$
\hat{e}_{n k}^{(p)}=\left\{\begin{array}{l}
z_{k}^{-1 / q}, 1 \leq k \leq n \\
0, k>n
\end{array}\right.
$$

and

$$
\hat{f}_{n k}=\left\{\begin{array}{l}
\frac{\mu\left(\frac{n}{k}\right) k}{\varphi(n)}, k \mid n \\
-\frac{\mu\left(\frac{n-1}{k}\right) k}{\varphi(n-1)}, k \mid n-1 \\
\frac{\mu(n)}{\varphi(n)}-\frac{\mu(n-1)}{\varphi(n-1)}, k=1 \\
0, \text { otherwise. }
\end{array}\right.
$$

Theorem 2.1 Let $1 \leq p<\infty$ and the matrices $E^{(p)}$ and $F$ be defined by (3) and (4), respectively. Then, the space $\left|\phi_{z}\right|_{p}$ is a $B K$ space with respect to the norm

$$
\|x\|_{\left|\phi_{z}\right|_{p}}=\left\|E^{(p)} \circ F(x)\right\|_{\ell_{p}}
$$

and norm isomorphic to the space $\ell_{p}$, that is, $\left|\phi_{z}\right|_{p} \cong \ell_{p}$.
Proof. Since $\ell_{p}$ is a $B K$ space and $E^{(p)} \circ F$ is a triangle matrix and $\left|\phi_{z}\right|_{p}=\left(\ell_{p}\right)_{E(p){ }_{\circ}{ }}$, the space $\left|\phi_{z}\right|_{p}$ is a $B K$ space by Theorem 4.3.2 in [2].

Further, consider the transformations $F:\left|\phi_{z}\right|_{p} \rightarrow$ $\left(\ell_{p}\right)_{E^{(p)}}$ and $E^{(p)}:\left(\ell_{p}\right)_{E^{(p)}} \rightarrow \ell_{p}$. Since $F$ and $E^{(p)}$ are linear bijections, then, it is clear that composite function $E^{(p)} \circ F$ is a linear bijective operator. In fact, if $\left(E^{(p)} \circ F\right)(x)=\theta$, then $x=\theta$, so $E^{(p)} \circ F$ is injective. Also, let $u=\left(u_{k}\right) \in \ell_{p}$ be given. Then, since $y=\left(y_{n}\right)=\left(\sum_{k=1}^{n} z_{k}^{-1 / q} u_{k}\right) \in\left(\ell_{p}\right)_{E}(p)$, we get

$$
\begin{aligned}
x=\left(x_{n}\right) & =\left(\sum_{k \mid n} \frac{\mu\left(\frac{n}{k}\right) k}{\varphi(n)} y_{k}-\sum_{k \mid n-1} \frac{\mu\left(\frac{n-1}{k}\right) k}{\varphi(n-1)} y_{k}\right) \\
& \in\left|\phi_{z}\right|_{p} .
\end{aligned}
$$

This gives that $u=\left(E^{(p)} \circ F\right)(x) \in \ell_{p}$, so $E^{(p)} \circ F$ is surjective. Furthermore, $E^{(p)} \circ F$ preserves the norm since

$$
\left\|E^{(p)} \circ F(x)\right\|_{\ell_{p}}=\|x\|_{\left|\phi_{z}\right|_{p}} .
$$

Note that the collection of all finite subsets of $\mathbb{N}$ is denoted by $\mathcal{N}$.

Lemma 2.2 [32]

a) $T=\left(t_{n k}\right) \in\left(\ell_{1}, c\right)$ if and only if

$$
\lim _{n} t_{n k} \text { exists for each } k \geq 1
$$

and

$$
\sup _{n, k}\left|t_{n k}\right|<\infty
$$

b) $T=\left(t_{n k}\right) \in\left(\ell_{1}, \ell_{\infty}\right)$ if and only if (8) holds.

c) Let $1<p<\infty . T=\left(t_{n k}\right) \in\left(\ell_{p}, c\right)$ if and only if (7) holds and

$$
\sup _{n} \sum_{k=1}^{\infty}\left|t_{n k}\right|^{q}<\infty .
$$

d) Let $1<p<\infty . T=\left(t_{n k}\right) \in\left(\ell_{p}, \ell_{\infty}\right)$ if and only if (9) holds.

e) Let $1<p<\infty . T=\left(t_{n k}\right) \in\left(\ell_{p}, \ell_{1}\right)$ if and only if

$$
\sup _{N \in \mathcal{N}} \sum_{k}\left|\sum_{n \in N} t_{n k}\right|^{q}<\infty .
$$

Lemma 2.3 [33] Let $1 \leq p<\infty . T=\left(t_{n k}\right) \in\left(\ell_{1}, \ell_{p}\right)$ if and only if

$$
\sup _{k} \sum_{n=1}^{\infty}\left|t_{n k}\right|^{p}<\infty .
$$

Using following notations and Lemmas 2.2-2.3, we state following theorem related to $\alpha, \beta$ and $\gamma$-duals of the series space $\left|\phi_{z}\right|_{p}$.

$$
\begin{gathered}
\Omega_{1}=\left\{a=\left(a_{j}\right) \in \omega: \lim _{m}\left(\sum_{j=r}^{m} \sum_{k=r}^{j} a_{j} \hat{f}_{j k}\right)\right. \text { exists, } \\
r \geq 1\},
\end{gathered}
$$




$$
\begin{gathered}
\Omega_{2}=\left\{a=\left(a_{j}\right) \in \omega: \sup _{m, r}\left|\sum_{j=r}^{m} \sum_{k=r}^{j} a_{j} \hat{f}_{j k}\right|<\infty\right\}, \\
\Omega_{3}=\left\{a=\left(a_{j}\right) \in \omega: \sup _{m} \sum_{r=1}^{m}\left|z_{r}^{-1 / q} \sum_{j=r}^{m} \sum_{k=r}^{j} a_{j} \hat{f}_{j k}\right|^{q}\right. \\
<\infty\}, \\
\Omega_{4}=\left\{a=\left(a_{j}\right) \in \omega: \sup _{r} \sum_{n=r}^{\infty}\left|\sum_{k=r}^{n} a_{n} \hat{f}_{n k}\right|<\infty\right\}, \\
\Omega_{5}=\left\{a=\left(a_{j}\right) \in \omega: \sup _{N \in \mathcal{N}} \sum_{r}\left|\sum_{n \in N} \sum_{k=r}^{n} a_{n} \hat{f}_{n k} z_{r}^{-1 / q}\right|^{q}\right. \\
<\infty\}
\end{gathered}
$$

Theorem 2.4 Let $\hat{F}=\left(\hat{f}_{n k}\right)$ be defined by (6). Then, we have:

a) $\left(\left|\phi_{z}\right|_{p}\right)^{\beta}=\Omega_{1} \cap \Omega_{3}$ for $1<p<\infty$ and $\left(\left|\phi_{z}\right|_{1}\right)^{\beta}=$ $\Omega_{1} \cap \Omega_{2}$.

b) $\left(\left|\phi_{z}\right|_{p}\right)^{\gamma}=\Omega_{3}$ for $1<p<\infty$ and $\left(\left|\phi_{z}\right|_{1}\right)^{\gamma}=\Omega_{2}$.

c) $\left(\left|\phi_{z}\right|_{p}\right)^{\alpha}=\Omega_{5}$ for $1<p<\infty$ and $\left(\left|\phi_{z}\right|_{1}\right)^{\alpha}=\Omega_{4}$.

Proof. a) Let $1<p<\infty . a \in\left(\left|\phi_{z}\right|_{p}\right)^{\beta}$ if and only if $a x \in c s$ for every $x \in\left|\phi_{z}\right|_{p}$. Let $y=F(x)$. Then, $u \in \ell_{p}$, where $u_{n}=z_{n}^{1 / q}\left(y_{n}-y_{n-1}\right)$ for $n \geq 1, y_{0}=0$, and also we have $y_{n}=\sum_{k=1}^{n} z_{k}^{-1 / q} u_{k}$. Since we have

$$
\begin{aligned}
x_{n} & =\sum_{k \mid n} \frac{\mu\left(\frac{n}{k}\right) k}{\varphi(n)} y_{k}-\sum_{k \mid n-1} \frac{\mu\left(\frac{n-1}{k}\right) k}{\varphi(n-1)} y_{k} \\
& =\sum_{k=1}^{n} \hat{f}_{n k} y_{k},
\end{aligned}
$$

we obtain that

$$
\begin{aligned}
\sum_{j=1}^{m} a_{j} x_{j} & =\sum_{j=1}^{m} a_{j} \sum_{k=1}^{j} \hat{f}_{j k} y_{k} \\
& =\sum_{k=1}^{m}\left\{\sum_{j=k}^{m} a_{j} \hat{f}_{j k}\right\} y_{k} \\
& =\sum_{r=1}^{m} z_{r}^{-1 / q}\left(\sum_{j=r}^{m} \sum_{k=r}^{j} a_{j} \hat{f}_{j k}\right) u_{r} \\
& =\sum_{r=1}^{m} d_{m r} u_{r},
\end{aligned}
$$

where the matrix $D=\left(d_{m r}\right)$ is given by

$$
d_{m r}=\left\{\begin{array}{l}
z_{r}^{-1 / q}\left(\sum_{j=r}^{m} \sum_{k=r}^{j} a_{j} \hat{f}_{j k}\right), 1 \leq r \leq m \\
0, \quad r>m .
\end{array}\right.
$$

So it is written by part c) of Lemma 2.2 that $a \in\left(\left|\phi_{z}\right|_{p}\right)^{\beta}$ iff $D \in\left(\ell_{p}, c\right)$, or equivalently, $a \in \Omega_{1} \cap \Omega_{3}$, which completes the proof.

Since the proof for $p=1$ is similar by using part a) of Lemma 2.2, we omit the detail.

b) Let $1<p<\infty$. Then, $a \in\left(\left|\phi_{z}\right|_{p}\right)^{\gamma}$ if and only if $a x \in b s$ for every $x \in\left|\phi_{z}\right|_{p}$. Also, $x \in\left|\phi_{z}\right|_{p}$ iff $u \in \ell_{p}$, where $u_{n}=z_{n}^{1 / q}\left(y_{n}-y_{n-1}\right) \quad, \quad y_{0}=0$ and $y_{n}=$ $\sum_{j=1}^{n} x_{j} \sum_{\substack{k=j \\ k \mid n}}^{n} \frac{\varphi(k)}{n}$ for $n \geq 1$. Thus, since we have

$$
\sum_{r=1}^{m} a_{r} x_{r}=\sum_{r=1}^{m} d_{m r} u_{r}
$$

where $D=\left(d_{m r}\right)$ is defined by (10), this implies that $a \in\left(\left|\phi_{z}\right|_{p}\right)^{\gamma}$ iff $D \in\left(\ell_{p}, \ell_{\infty}\right)$. Hence, it follows from part d) of Lemma 2.2 that $a \in \Omega_{3}$ as asserted.

Since the proof for $p=1$ is similar by using part b) of Lemma 2.2, we omit the detail.

c) Let $1<p<\infty$. Then, $a \in\left(\left|\phi_{z}\right|_{p}\right)^{\alpha}$ if and only if $a x \in \ell_{1}$ for every $x \in\left|\phi_{z}\right|_{p}$. Then, we get

$$
\begin{aligned}
a_{n} x_{n} & =a_{n} \sum_{k=1}^{n} \hat{f}_{n k} y_{k}=a_{n} \sum_{k=1}^{n} \hat{f}_{n k} \sum_{r=1}^{k} z_{r}^{-1 / q} u_{r} \\
& =\sum_{r=1}^{n} \sum_{k=r}^{n} a_{n} \hat{f}_{n k} z_{r}^{-1 / q} u_{r}=\delta_{n}(u),
\end{aligned}
$$

where $\delta_{n}=\left(\delta_{n r}\right)$ is defined by

$$
\delta_{n r}=\sum_{k=r}^{n} a_{n} \hat{f}_{n k} z_{r}^{-1 / q} \text {. }
$$

So, $a x \in \ell_{1}$ for every $x \in\left|\phi_{z}\right|_{p}$ if and only if $\delta(u) \in \ell_{1}$ for every $u \in \ell_{p}$, or equivalently, $a \in\left(\left|\phi_{z}\right|_{p}\right)^{\alpha}$ iff $\delta \in\left(\ell_{p}, \ell_{1}\right)$, which gives $a \in \Omega_{5}$ from Lemma 2.2, as desired.

Since the proof for $p=1$ is similar by using Lemma 2.3, we omit the detail.

Theorem 2.5 Let $1 \leq p<\infty, \quad \hat{F}=\left(\hat{f}_{n k}\right)$ and $\tau^{(r)}=\left(\tau_{j}^{(r)}\right)$ be defined by (6) and $\tau_{j}^{(r)}=\left\{\begin{array}{l}z_{r}^{-1 / q} \sum_{k=r}^{j} \hat{f}_{j k}, r \leq j, \\ 0, r>j .\end{array}\right.$ sequence $\left(\tau_{j}^{(r)}\right)$ is a Schauder base of the space $\left|\phi_{z}\right|_{p}$.

Proof. It is known that the sequence $\left(e^{(n)}\right)$ is a Schauder base for the space $\ell_{p}$, where $e^{(n)}$ is a sequence with 1 in $n$-th place and zeros elsewhere. Because of the transformation $E^{(p)} \circ F$ defined in the proof of Theorem 2.1 is an isomorphism, the inverse image $\left(E^{(p)} \circ F\right)^{-1}$ of $\left(e^{(n)}\right)$ is a Schauder basis for $\left|\phi_{z}\right|_{p}$. In fact, if $x \in\left|\phi_{z}\right|_{p}$, 
then there exists $u \in \ell_{p}$ such that $u=\left(E^{(p)} \circ F\right)(x)$, so we can deduce from Theorem 2.1 that

$$
\left\|x-\sum_{r=1}^{m} x_{r} \tau^{(r)}\right\|_{\left|\phi_{z}\right|_{p}}=\left\|u-\sum_{r=1}^{m} u_{r} e^{(r)}\right\|_{\ell_{p}} \rightarrow 0
$$

as $\quad m \rightarrow \infty$, where $\left(E^{(p)} \circ F\right)^{-1}\left(e^{(r)}\right)=\tau^{(r)}, r \geq 1$. Furthermore, every $x \in\left|\phi_{z}\right|_{p}$ has a unique representation of the form $x=\sum_{r=1}^{\infty} x_{r} \tau^{(r)}$.

\section{Some Matrix Operators}

In this section, we firstly characterize the matrix classes from the space $\left|\phi_{z}\right|_{p}$ to the classical spaces $\ell_{\infty}, c, c_{0}, \ell_{1}$ for $1 \leq p<\infty$.

\section{Lemma 3.1 [32]}

a) $T=\left(t_{n k}\right) \in\left(\ell_{1}, c_{0}\right)$ if and only if (8) holds and

$$
\lim _{n} t_{n k}=0 \text { for each } k \geq 1 \text {. }
$$

b) Let $1<p<\infty . T=\left(t_{n k}\right) \in\left(\ell_{p}, c_{0}\right)$ if and only if (9) and (11) hold.

Theorem 3.2 Let define the matrix $R^{1}=\left(r_{n k}^{1}\right)$ with a matrix $T=\left(t_{n k}\right)$ as

$$
r_{n k}^{1}=\lim _{m \rightarrow \infty} \sum_{j=k}^{m} t_{n j} \sum_{l=k}^{j} \hat{f}_{j l}
$$

for all $n, k \in \mathbb{N}$.

- $T \in\left(\left|\phi_{z}\right|_{1}, \ell_{\infty}\right)$ if and only if

$R^{1}=\left(r_{n k}^{1}\right)$ is well defined for all $n, k \in \mathbb{N}$

$$
\begin{aligned}
& \sup _{m, k}\left|\sum_{j=k}^{m} t_{n j} \sum_{l=k}^{j} \hat{f}_{j l}\right|<\infty \text { for each } n \in \mathbb{N} \\
& \sup _{n, k}\left|r_{n k}^{1}\right|<\infty .
\end{aligned}
$$

- $T \in\left(\left|\phi_{z}\right|_{1}, c\right)$ if and only if (12), (13) and (14) hold, and

$$
\lim _{n \rightarrow \infty} r_{n k}^{1} \text { exists for each } k \in \mathbb{N} \text {. }
$$

- $T \in\left(\left|\phi_{z}\right|_{1}, c_{0}\right)$ if and only if (12), (13) and (14) hold, and

$$
\lim _{n \rightarrow \infty} r_{n k}^{1}=0 \text { for each } k \in \mathbb{N} .
$$

- $T \in\left(\left|\phi_{z}\right|_{1}, \ell_{1}\right)$ if and only if (12) and (13) hold, and

$$
\sup _{k} \sum_{n}\left|r_{n k}^{1}\right|<\infty \text {. }
$$

Proof. The proof is given only for the first case since others can be proved similarly.

- $T \in\left(\left|\phi_{z}\right|_{1}, \ell_{\infty}\right)$ if and only if $T x \in \ell_{\infty}$ for all $x \in\left|\phi_{z}\right|_{1}$. Since the series $\sum_{k=0}^{\infty} t_{n k} x_{k}$ is convergent, we have that $\left(t_{n k}\right) \in\left(\left|\phi_{z}\right|_{1}\right)^{\beta}$ for each fixed $n \in \mathbb{N}$. By Theorem 2.4, we obtain that

$$
\lim _{m \rightarrow \infty} \sum_{j=k}^{m} \sum_{l=k}^{j} t_{n j} \hat{f}_{j l}
$$

exists for each $n, k \in \mathbb{N}$ and

$$
\sup _{m, k}\left|\sum_{j=k}^{m} \sum_{l=k}^{j} t_{n j} \hat{f}_{j l}\right|<\infty \text { for each } n \in \mathbb{N} .
$$

That is, (12) and (13) hold. Now, we prove the necessity and sufficiency of (14). Consider the linear operator $E^{(1)} \circ F:\left|\phi_{z}\right|_{1} \rightarrow \ell_{1}$. Let $\quad y=F x \quad$ and $v=\Delta y=\left(E^{(1)} \circ F\right) x$ for any $x \in\left|\phi_{z}\right|_{1}$. Then we have $y_{n}=\sum_{k=1}^{n} v_{k}$. Hence it follows that

$$
\begin{gathered}
\sum_{k=1}^{m} t_{n k} x_{k}=\sum_{k=1}^{m} t_{n k} \sum_{j=1}^{k} \hat{f}_{k j} y_{j} \\
=\sum_{k=1}^{m} t_{n k} \sum_{j=1}^{k} \hat{f}_{k j} \sum_{l=1}^{j} v_{l} \\
=\sum_{k=1}^{m} t_{n k} \sum_{j=1}^{k} \sum_{l=j}^{k} \hat{f}_{k l} v_{j} \\
=\sum_{j=1}^{m}\left(\sum_{k=j}^{m} t_{n k} \sum_{l=j}^{k} \hat{f}_{k l}\right) v_{j} \\
=\sum_{j=1}^{m} \tilde{r}_{m j}^{1} v_{j},
\end{gathered}
$$

where

$$
\tilde{r}_{m j}^{1}= \begin{cases}\sum_{k=j}^{m} t_{n k} \sum_{l=j}^{k} \hat{f}_{k l}, & 1 \leq j \leq m \\ 0 \quad, j>m\end{cases}
$$

for each $n \in \mathbb{N}$. Also, it can be deduced by (12) and (13) that $\tilde{R}^{1}=\left(\tilde{r}_{m j}^{1}\right) \in\left(\ell_{1}, c\right)$. Then the series $\tilde{R}_{m}^{1}(v)=$ $\sum_{j=1}^{\infty} \tilde{r}_{m j}^{1} v_{j}$ converges uniformly in $m$ for all $v \in \ell_{1}$ and so we have $\lim _{m \rightarrow \infty} \tilde{R}_{m}^{1}(v)=\sum_{j=1}^{\infty} \lim _{m \rightarrow \infty} \tilde{r}_{m j}^{1} v_{j}$. Thus, we obtain that

$$
\begin{gathered}
T_{n}(x)=\lim _{m \rightarrow \infty} \tilde{R}_{m}^{1}(v)=\sum_{j=1}^{\infty}\left(\lim _{m \rightarrow \infty} \tilde{r}_{m j}^{1}\right) v_{j} \\
=\sum_{j=1}^{\infty} r_{n j}^{1} v_{j}=R_{n}^{1}(v) .
\end{gathered}
$$

This yields that $T x \in \ell_{\infty}$ for $x \in\left|\phi_{z}\right|_{1}$ if and only if $R^{1} v \in \ell_{\infty}$ for $v \in \ell_{1}$. We conclude that $T \in\left(\left|\phi_{z}\right|_{1}, \ell_{\infty}\right)$ if and only (12) and (13) hold and also $R^{1} \in\left(\ell_{1}, \ell_{\infty}\right)$ which means (14).

Theorem 3.3 Let $1<p<\infty$ and define the matrix $R^{p}=\left(r_{n k}^{p}\right)$ with a matrix $T=\left(t_{n k}\right)$ as

$$
r_{n k}^{p}=z_{k}^{-1 / q} \lim _{m \rightarrow \infty} \sum_{j=k}^{m} t_{n j} \sum_{l=k}^{j} \hat{f}_{j l}
$$


for all $n, k \in \mathbb{N}$.

- $T \in\left(\left|\phi_{z}\right|_{p}, \ell_{\infty}\right)$ if and only if (12) holds and $\sup _{m} \sum_{k=1}^{m}\left|z_{k}^{-\frac{1}{q}} \sum_{j=k}^{m} t_{n j} \sum_{l=k}^{j} \hat{f}_{j l}\right|^{q}<\infty$ for each $n \in \mathbb{N}$,

$$
\sup _{n} \sum_{k}\left|r_{n k}^{p}\right|^{q}<\infty .
$$

- $T \in\left(\left|\phi_{z}\right|_{p}, c\right)$ if and only if (12), (15) and (16) hold, and

$$
\lim _{n \rightarrow \infty} r_{n k}^{p} \text { exists for each } k \in \mathbb{N} \text {. }
$$

- $T \in\left(\left|\phi_{z}\right|_{p}, c_{0}\right)$ if and only if (12), (15) and (16) hold, and

$$
\lim _{n \rightarrow \infty} r_{n k}^{p}=0 \text { for each } k \in \mathbb{N} \text {. }
$$

- $T \in\left(\left|\phi_{z}\right|_{p}, \ell_{1}\right)$ if and only if (12) and (15) hold, and

$$
\sup _{N \in \mathcal{N}} \sum_{k}\left|\sum_{n \in N} r_{n k}^{p}\right|^{q}<\infty .
$$

Proof. The proof is given only for the first case since others can be proved similarly.

- $T \in\left(\left|\phi_{z}\right|_{p}, \ell_{\infty}\right)$ if and only if $T x \in \ell_{\infty}$ for all $x \in\left|\phi_{z}\right|_{p}$. Since the series $\sum_{k=1}^{\infty} t_{n k} x_{k}$ is convergent, we have that $\left(t_{n k}\right) \in\left(\left|\phi_{z}\right|_{p}\right)^{\beta}$ for each fixed $n \in \mathbb{N}$. From Theorem 2.4, we obtain that (12) holds and

$$
\sup _{m} \sum_{k=1}^{m}\left|z_{k}^{-1 / q} \sum_{j=k}^{m} \sum_{l=k}^{j} t_{n j} \hat{f}_{j l}\right|^{q}<\infty,
$$

for each $n \in \mathbb{N}$.

Now, we prove the necessity and sufficiency of (16). Consider the linear operator $E^{(p)} \circ F:\left|\phi_{z}\right|_{p} \rightarrow \ell_{p}$ defined by $\left(E^{(p)} \circ F\right)_{n}(x)=z_{n}^{1 / q}\left(F_{n}(x)-F_{n-1}(x)\right)$, $n \geq 1$ and $F_{0}(x)=0$. Let $y=F x$ and $v=\left(E^{(p)} \circ F\right) x$ for any $x \in\left|\phi_{z}\right|_{p}$. Then we have $y_{n}=\sum_{k=1}^{n} z_{k}^{-1 / q} v_{k}$. Hence it follows that

$$
\begin{gathered}
\sum_{k=1}^{m} t_{n k} x_{k}=\sum_{k=1}^{m} t_{n k} \sum_{j=1}^{k} \hat{f}_{k j} y_{j} \\
=\sum_{k=1}^{m} t_{n k} \sum_{j=1}^{k} \hat{f}_{k j} \sum_{l=1}^{j} z_{l}^{-1 / q} v_{l} \\
=\sum_{k=1}^{m} t_{n k} \sum_{j=1}^{k} \sum_{l=j}^{k} \hat{f}_{k l} z_{j}^{-1 / q} v_{j} \\
=\sum_{j=1}^{m}\left(z_{j}^{-1 / q} \sum_{k=j}^{m} t_{n k} \sum_{l=j}^{k} \hat{f}_{k l}\right) v_{j} \\
=\sum_{j=1}^{m} \tilde{r}_{m j}^{p} v_{j},
\end{gathered}
$$

where $\tilde{r}_{m j}^{p}= \begin{cases}z_{j}^{-1 / q} \sum_{k=j}^{m} t_{n k} \sum_{l=j}^{k} \hat{f}_{k l} & , \quad 1 \leq j \leq m \\ 0 & , \quad j>m\end{cases}$

for each $n \in \mathbb{N}$. Also, it can be deduced by (12) and (15) that $\tilde{R}^{p}=\left(\tilde{r}_{m j}^{p}\right) \in\left(\ell_{p}, c\right)$. Then the series $\tilde{R}_{m}^{p}(v)=$ $\sum_{j=1}^{\infty} \tilde{r}_{m j}^{p} v_{j}$ converges uniformly in $m$ for all $v \in \ell_{p}$ and so we have $\lim _{m \rightarrow \infty} \tilde{R}_{m}^{p}(v)=\sum_{j=1}^{\infty} \lim _{m \rightarrow \infty} \tilde{r}_{m j}^{p} v_{j}$. Thus, we obtain that

$$
\begin{gathered}
T_{n}(x)=\lim _{m \rightarrow \infty} \tilde{R}_{m}^{p}(v)=\sum_{j=1}^{\infty}\left(\lim _{m \rightarrow \infty} \tilde{r}_{m j}^{p}\right) v_{j}=\sum_{j=1}^{\infty} r_{n j}^{p} v_{j} \\
=R_{n}^{p}(v) .
\end{gathered}
$$

This yields that $T x \in \ell_{\infty}$ for $x \in\left|\phi_{z}\right|_{p}$ if and only if $R^{p} v \in \ell_{\infty}$ for $v \in \ell_{p}$. We conclude that $T \in\left(\left|\phi_{z}\right|_{p}, \ell_{\infty}\right)$ if and only (12) and (15) hold and also $R^{p} \in\left(\ell_{p}, \ell_{\infty}\right)$ which means (16).

Now, we give the characterization of the matrix classes from the classical spaces $\ell_{\infty}, c, c_{0}, \ell_{1}$ to the space $\left|\phi_{z}\right|_{p}$ for $1 \leq p<\infty$. We need the following lemma to prove our results.

Lemma 3.4 [32]

a) $T=\left(t_{n k}\right) \in\left(\ell_{\infty}, \ell_{1}\right)=\left(c, \ell_{1}\right)=\left(c_{0}, \ell_{1}\right)$ if and only if

$$
\sup _{K \in \mathcal{N}} \sum_{n=1}^{\infty}\left|\sum_{k \in K} t_{n k}\right|<\infty .
$$

b) Let $p>1$. $T=\left(t_{n k}\right) \in\left(\ell_{\infty}, \ell_{p}\right)=\left(c, \ell_{p}\right)=\left(c_{0}, \ell_{p}\right)$ if and only if

$$
\sup _{K \in \mathcal{N}} \sum_{n=1}^{\infty}\left|\sum_{k \in K} t_{n k}\right|^{p}<\infty .
$$

Theorem 3.5 Let $T=\left(t_{n k}\right)$ be an infinite matrix.

- $T \in\left(\ell_{\infty},\left|\phi_{z}\right|_{1}\right)=\left(c,\left|\phi_{z}\right|_{1}\right)=\left(c_{0},\left|\phi_{z}\right|_{1}\right)$ if and only if

$$
\sup _{K \in \mathcal{N}} \sum_{n=1}^{\infty}\left|\sum_{k \in K}\left\{\sum_{j=1}^{n}\left(\sum_{l=j, l \mid n}^{n} \frac{\varphi(l)}{n}-\sum_{l=j, l \mid n-1}^{n-1} \frac{\varphi(l)}{n-1}\right) t_{j k}\right\}\right|
$$

- $T \in\left(\ell_{1},\left|\phi_{z}\right|_{1}\right)$ if and only if

$$
\sup _{k} \sum_{n=1}^{\infty}\left|\sum_{j=1}^{n}\left(\sum_{l=j, l \mid n}^{n} \frac{\varphi(l)}{n}-\sum_{l=j, l \mid n-1}^{n-1} \frac{\varphi(l)}{n-1}\right) t_{j k}\right|
$$

$<\infty$.

Proof. The proof is given only for the matrix class $\left(\ell_{\infty},\left|\phi_{z}\right|_{1}\right)$ since the other cases can be proved similarly. Consider the matrix $S^{1}=\left(s_{n k}^{1}\right)$ defined as

$$
s_{n k}^{1}=\sum_{j=1}^{n}\left(\sum_{l=j, l \mid n}^{n} \frac{\varphi(l)}{n}-\sum_{l=j, l \mid n-1}^{n-1} \frac{\varphi(l)}{n-1}\right) t_{j k}<\infty .
$$

for all $n, k \in \mathbb{N}$. Let $x=\left(x_{n}\right) \in \ell_{\infty}$. We obtain the following equality:

$$
\sum_{k=1}^{\infty} s_{n k}^{1} x_{k}
$$




$$
\begin{gathered}
=\sum_{k=1}^{\infty}\left(\sum_{j=1}^{n}\left(\sum_{l=j, l \mid n}^{n} \frac{\varphi(l)}{n}-\sum_{l=j, l \mid n-1}^{n-1} \frac{\varphi(l)}{n-1}\right) t_{j k}\right) x_{k} \\
=\sum_{j=1}^{n} \sum_{k=1}^{\infty} t_{j k} x_{k} \sum_{l=j, l \mid n}^{n} \frac{\varphi(l)}{n} \\
-\sum_{j=1}^{n-1} \sum_{k=1}^{\infty} t_{j k} x_{k} \sum_{l=j, l \mid n-1}^{n-1} \frac{\varphi(l)}{n-1} \\
=F_{n}(T x)-F_{n-1}(T x) .
\end{gathered}
$$

This implies that $S_{n}^{1}(x)=\left(E^{(1)} \circ F\right)_{n}(T x)$ for all $n \in \mathbb{N}$. Hence, it follows that $T x \in\left|\phi_{z}\right|_{1}$ for any $x \in \ell_{\infty}$ if and only if $S^{1} x \in \ell_{1}$ for any $x \in \ell_{\infty}$. We conclude that

$$
\begin{aligned}
\sup _{K \in \mathcal{N}} \sum_{n=1}^{\infty} \mid \sum_{k \in K}\left\{\sum _ { j = 1 } ^ { n } \left(\sum_{l=j, l \mid n}^{n} \frac{\varphi(l)}{n}\right.\right. & \\
& \left.\left.-\sum_{l=j, l \mid n-1}^{n-1} \frac{\varphi(l)}{n-1}\right) t_{j k}\right\} \mid<\infty
\end{aligned}
$$

since we have $S^{1} \in\left(\ell_{\infty}, \ell_{1}\right)$.

Theorem 3.6 Let $T=\left(t_{n k}\right)$ be an infinite matrix and $1<p<\infty$.

- $T \in\left(\ell_{\infty},\left|\phi_{z}\right|_{p}\right)=\left(c,\left|\phi_{z}\right|_{p}\right)=\left(c_{0},\left|\phi_{z}\right|_{p}\right)$ if and only if

$$
\begin{aligned}
\sup _{K \in \mathcal{N}} \sum_{n=1}^{\infty} \mid \sum_{k \in K}\left\{\sum _ { j = 1 } ^ { n } z _ { n } ^ { 1 / q } \left(\sum_{l=j, l \mid n}^{n} \frac{\varphi(l)}{n}\right.\right. & \\
& \left.\left.-\sum_{l=j, l \mid n-1}^{n-1} \frac{\varphi(l)}{n-1}\right) t_{j k}\right\}\left.\right|^{p}<\infty .
\end{aligned}
$$

- $T \in\left(\ell_{1},\left|\phi_{z}\right|_{p}\right)$ if and only if

$$
\left.\sup _{k} \sum_{n=1}^{\infty} \mid \sum_{j=1}^{n} z_{n}^{1 / q} \sum_{\substack{l=j, l \mid n \\<\infty}} \frac{\varphi(l)}{n}-\sum_{l=j, l \mid n-1}^{n-1} \frac{\varphi(l)}{n-1}\right)\left.t_{j k}\right|^{p}
$$

Proof. The proof is given only for the matrix class $\left(\ell_{1},\left|\phi_{z}\right|_{p}\right)$ since the other cases can be proved similarly.

Let $p>1$. Consider the matrix $S^{p}=\left(s_{n k}^{p}\right)$ defined as

$$
s_{n k}^{p}=\sum_{j=1}^{n} z_{n}^{1 / q}\left(\sum_{l=j, l \mid n}^{n} \frac{\varphi(l)}{n}-\sum_{l=j, l \mid n-1}^{n-1} \frac{\varphi(l)}{n-1}\right) t_{j k}
$$

for all $n, k \in \mathbb{N}$. Let $x=\left(x_{n}\right) \in \ell_{1}$. We obtain the following equality:

$$
\begin{gathered}
\sum_{k=1}^{\infty} s_{n k}^{p} x_{k} \\
=\sum_{k=1}^{\infty}\left(\sum _ { j = 1 } ^ { n } z _ { n } ^ { 1 / q } \left(\sum_{l=j, l \mid n}^{n} \frac{\varphi(l)}{n}\right.\right. \\
\left.\left.-\sum_{l=j, l \mid n-1}^{n-1} \frac{\varphi(l)}{n-1}\right) t_{j k}\right) x_{k}
\end{gathered}
$$

$$
\begin{gathered}
=z_{n}^{1 / q}\left(\sum_{j=1}^{n} \sum_{k=1}^{\infty} t_{j k} x_{k} \sum_{l=j, l \mid n}^{n} \frac{\varphi(l)}{n}\right. \\
\left.\quad-\sum_{j=1}^{n-1} \sum_{k=1}^{\infty} t_{j k} x_{k} \sum_{l=j, l \mid n-1}^{n-1} \frac{\varphi(l)}{n-1}\right) \\
=z_{n}^{1 / q}\left(F_{n}(T x)-F_{n-1}(T x)\right) .
\end{gathered}
$$

This implies that $S_{n}^{p}(x)=\left(E^{(p)} \circ F\right)_{n}(T x)$ for all $n \in \mathbb{N}$. Hence, it follows that $T x \in\left|\phi_{z}\right|_{p}$ for any $x \in \ell_{1}$ if and only if $S^{p} x \in \ell_{p}$ for any $x \in \ell_{1}$. We conclude that

$$
\sup _{k} \sum_{n=1}^{\infty}\left|\sum_{j=1}^{n} z_{n}^{1 / q}\left(\sum_{\substack{l=j, l \mid n \\<\infty,}}^{n} \frac{\varphi(l)}{n}-\sum_{l=j, l \mid n-1}^{n-1} \frac{\varphi(l)}{n-1}\right) t_{j k}\right|^{p}
$$

since we have $S^{p} \in\left(\ell_{1}, \ell_{p}\right)$.

\section{Conclusion}

In this paper new series spaces are introduced by using a new summability method derived by Euler totient matrix. After determining dual spaces and some topological properties of the resulting spaces, characterization of certain matrix classes on these spaces are obtained.

\section{References}

[1] Altay, B. Başar, F. and Malkowsky, E., "Matrix transformations on some sequence spaces related to strong Cesàro summability and boundedness", Appl. Math. Comput, 211(2), 255-264, 2009.

[2] Wilansky, A., Summability Through Functional Analysis, North-Holland Mathematical Studies, vol.85, Elsevier Science Publisher, 1984.

[3] Schoenberg, I., "The integrability of certain functions and related summability methods", Amer. Math. Monthly, 66, 361-375, 1959.

[4] İlkhan, M. and Kara, E.E., "A new Banach space defined by Euler totient matrix operator", Oper. Matrices, 13(2), 527-544, 2019.

[5] Sarıgöl, M.A., "On the local properties of factored Fourier series", Appl. Math. Comp., 216, 3386-3390, 2010.

[6] Bor, H., "On $\left|N, p_{n}\right|_{k}$ summability factors of infinite series", Tamkang J. Math., 16, 13-20, 1985.

[7] Sulaiman, W.T., "On summability factors of infinite series", Proc. Amer. Math. Soc., 115, 313-317, 1992.

[8] Borwein, D. and Cass, F.P., "Strong Nörlund summability", Math. Zeitschr., 103, 94-111, 1968.

[9] Flett, T.M., "On an extension of absolute summability and some theorems of Littlewood and Paley", Proc. London Math. Soc., 7, 113-141, 1957.

[10] Başarır, M. and Kara, E.E., "On some difference sequence spaces of weighted means and compact operators", Ann. Funct. Anal., 2, 114-129, 2011.

[11] Başarır, M. and Kara, E.E., "On compact operators on the Riesz $B^{m}$-difference sequence spaces", Iran. J. Sci. Technol. Trans. A Sci., 35, 279-285, 2011. 
[12] Bektaş, Ç.A., Et, M. and Çolak, R., "Generalized difference sequence spaces and their dual spaces", J. Math. Anal. Appl., 292(2), 423-432, 2004.

[13] Et, M., "On some difference sequence spaces" Turk. J. Math., 17, 18-24, 1993.

[14] Hazar, G.C. and Sarıgöl, M.A., "Absolute Cesàro series spaces and matrix operators", Acta App. Math., 154, 153-165, 2018.

[15] Kara, E.E. and Başarır, M., "On compact operators and some Euler B( $m$ ) difference sequence spaces", J. Math. Anal. Appl., 379(2), 499-511, 2011.

[16] Kara, E.E. and İlkhan, M., "Some properties of generalized Fibonacci sequence spaces", Linear Multilinear Algebra., 64(11), 2208-2223, 2016.

[17] Kirişçi, M. and Başar, F., "Some new sequence spaces derived by the domain of generalized difference matrix", Comput. Math. Appl., 60, 1299-1309, 2010.

[18] Kirişçi, M., "Riesz type integrated and differentiated sequence spaces", Bull. Math. Anal. Appl., 7(2), 1427, 2015.

[19] Mursaleen, M. and Noman, A.K., "Compactness by the Hausdorff measure of noncompactness", Nonlinear Anal., 73(8), 2541-2557, 2010.

[20] Mursaleen, M. and Noman A.K., "Applications of the Hausdorff measure of noncompactness in some sequence spaces of weighted means", Comput. Math. Appl., 60(5), 1245-1258, 2010.

[21] Mursaleen, M. and Noman A.K., "On the spaces of $\lambda$ convergent and bounded sequences", Thai J. Math., 8(2), 311-329, 2012.

[22] Mohiuddine, S.A., "An application of almost convergence in approximation theorems", Appl. Math. Lett., 24, 1856-1860, 2011.

[23] Mohiuddine, S.A. and Alotaibi, A., "Weighted almost convergence and related infinite matrices", $J$. Inequal. Appl., Article Number.15, 2018.
[24] Hazar, G.C. and Sarıgöl, M.A., "On absolute Nörlund spaces and matrix operators", Acta Math. Sin. (Engl. Ser.), 34(5), 812-826, 2018.

[25] Sarıgöl, M.A., "Spaces of Series Summable by Absolute Cesàro and Matrix Operators", Comm. Math Appl., 7(1), 11-22, 2016.

[26] İlkhan, M. Demiriz, S. and Kara, E.E., "A new paranormed sequence space defined by Euler totient function", Karaelmas Sci. Eng. J., 9(2), 277282, 2019.

[27] Ellidokuzoğlı, H.B. and Demiriz, S., "Euler-Riesz difference sequence spaces", Turk. J. Math. Comput. Sci., 7, 63-72, 2017.

[28] Demiriz, S. and Çakan, C. "Some topological and geometrical properties of a new difference sequence space", Abstr. Appl. Anal., 2011, Article ID 213878, 14 pages.

[29] Duyar, O. Demiriz, S. and Özdemir, O. “On some new generalized difference sequence spaces of nonabsolute type", J. Math., 2014, Article ID 876813, 13 pages.

[30] Ercan, S. and Bektaş Ç.A., "On $\lambda$-convergence and $\lambda$ boundedness of $m$ th order", Comm. Statist. Theory Methods, 2019, doi:10.1080/03610926.2019.1692032.

[31] Ercan, S., "On $\lambda_{r}$-convergence and $\lambda_{r}$-boundedness", J. Adv. Phys., 7(1), 123-129, 2018.

[32] Stieglitz, M. and Tietz, H., "Matrixtransformationen von folgenraumen eine ergebnisüberischt", Math $Z$., 154, 1-16, 1977.

[33] Maddox, I.J., Elements of functinal analysis, Cambridge University Press, London, New York, 1970. 